\title{
Pengendalian Penyakit Budok dengan Fungisida dan Deteksi Residu pada Daun Nilam
}

\section{Control of Budok Disease with Fungicides and Detection of Residue in Patchouli Leaves}

\author{
Christanti Sumardiyono ${ }^{*}$, Sedyo Hartono ${ }^{1}$, Nasrun $^{2}$, Sukamto ${ }^{3}$ \\ ${ }^{1}$ Universitas Gadjah Mada, Yogyakarta 55281 \\ ${ }^{2}$ Balai Penelitian Tanaman Obat dan Aromatik, Bogor 16111 \\ ${ }^{3}$ Kebun Percobaan Balittro, Solok 27301
}

\begin{abstract}
ABSTRAK
Budok yang disebabkan oleh Synchytrium pogostemonis merupakan penyakit terpenting pada tanaman nilam. Pengendalian kimiawi dilakukan apabila diprediksi akan terjadi serangan berat. Penelitian dilakukan menggunakan fungisida benomil (Benlate $50 \mathrm{WP}$ ) dan tembaga oksida (Kocide $77 \mathrm{WP}$ ) pada kepekatan $0.1 \%, 0.2 \%$ dan campuran $1 \mathrm{~g}$ tembaga oksida dan $1 \mathrm{~g} \mathrm{~L}^{-1}$ benomil. Penyemprotan dilakukan pada tanaman delapan kali dengan selang waktu satu minggu. Panen dilakukan 2 minggu setelah akhir penyemprotan. Residu tembaga pada daun kering dianalisis dengan AAS dan residu benomil dianalisis dengan HPLC. Hasil penelitian menunjukkan bahwa benomil $0.1 \%$ dapat menurunkan intensitas penyakit secara nyata dibandingkan dengan benomil $0.2 \%$, tembaga oksida, dan campuran keduanya. Benomil meningkatkan hasil lebih baik dibandingkan dengan perlakuan yang lain. Residu tembaga dalam daun kering terdeteksi bervariasi sesuai perlakuan, yaitu antara $460 \mathrm{ppm}$ dan $950 \mathrm{ppm}$. Residu benomil ialah 54-100 ppb. Bibit nilam sakit yang berasal dari stek sakit masih dapat digunakan bila disemprot dengan $0.1 \%$ benomil empat kali dengan selang waktu 2 minggu.
\end{abstract}

Kata kunci: pengendalian kimia, Synchytrium pogostemonis, minyak nilam, residu pestisida

\begin{abstract}
Budok caused by Synchytrium pogostemonis is the important and destructive disease on patchouli plant (Pogostemon cablin). Chemical control must be done in incidence with high disease intensity and prediction of outbreak. The experiment was done using benomyl (Benlate $50 \mathrm{WP}$ ) and cuprous oxide (Kocide $77 \mathrm{WP}$ ) $0.1 \%, 0.2 \%$ and mixture of both ( $1 \mathrm{~g}$ cuprous oxide and $1 \mathrm{~g} \mathrm{~L}^{-1}$ benomyl). Patchouli plant was sprayed eight times with one week interval. Harvesting was done two weeks after the end of spraying. Residue analysis of $\mathrm{Cu}$ was done with AAS and benomyl residue with HPLC. The result showed that $0.1 \%$ benomyl significantly reduced the disease intensity. The other treatments showed lower result. Harvested patchouli plants treated with $0.1 \%$ benomyl showed higher yield compare with $0.2 \%$ benomyl and cuprous oxyde. $\mathrm{Cu}$ residue in dried leaves was between $460 \mathrm{ppm}$ and $950 \mathrm{ppm}$. Residue of benomyl was $54-100 \mathrm{ppb}$. Diseased seedling still can be used after spraying by benomyl four times with 2 weeks interval.
\end{abstract}

Key words: chemical control, patchuoli oil, pesticide residue, Synchytrium pogostemonis

*Alamat penulis korespondensi: Jurusan Hama dan Penyakit Tumbuhan, Universitas Gadjah Mada, Jalan Flora, Bulaksumur, Yogyakarta 55281

Tel: 0274-523926, Faks: 0274-523926, Surel: csumardiyono@yahoo.com 


\section{PENDAHULUAN}

Nilam (Pogostemon cablin) merupakan salah satu komoditas andalan penghasil minyak atsiri (patchouli oil) yang bernilai ekonomi tinggi. Minyak nilam adalah bahan baku yang penting untuk industri kosmetika, parfum, sabun, dan shampo.

Penyakit budok atau karat palsu merupakan salah satu penyakit yang penting pada nilam yang disebabkan oleh Synchytrium pogostemonis (Wahyuno 2010). Pada batang tanaman sakit terdapat pembengkakan sehingga permukaan batang menjadi kasar dengan tonjolan-tonjolan berwarna cokelat kehitaman. Penyakit ini dapat dikendalikan dengan fungisida benomil dan tidak mengurangi kualitas minyak nilam yang dihasilkan (Kusnanta 2005).

Pengendalian penyakit pada tanaman dilakukan berdasarkan konsep pengendalian terpadu (PHT). Pengendalian kimia dengan fungisida dapat dilakukan apabila terjadi serangan berat dan diprediksi akan terjadi epidemi. Salah satu dampak pengendalian kimia adalah adanya residu pestisida pada produk yang dihasilkan. Hal ini merupakan kendala dalam produk pertanian yang diekspor.

Nilam adalah salah satu komoditas ekspor sebagai sumber devisa negara. Oleh karena itu, pengendalian kimia sudah seharusnya diikuti dengan análisis residu pestisida. Sampai saat ini belum dilaporkan batas maksimum residu (BMR) yang diperbolehkan terdapat pada minyak nilam.

Penelitian ini dilakukan untuk menguji kemampuan fungisida benomil, $\mathrm{Cu}$-oksida, dan campuran keduanya untuk pengendalian penyakit budok pada nilam. Analisis residu dilakukan pada daun kering sebagai masukan data bila negara tujuan ekspor mengharuskan dicantumkannya besaran residu fungisida pada produk nilam.

\section{BAHAN DAN METODE}

\section{Penyakit Budok pada Pertanaman Nilam}

Penelitian dilakukan pada pertanaman nilam di Desa Sawangan, Kabupaten
Magelang, Jawa Tengah. Lokasi ini dipilih berdasarkan pengamatan adanya kerusakan tinggi yang disebabkan oleh penyakit budok.

Percobaan dirancang dengan rancangan acak lengkap berblok dengan 6 perlakuan: B1, benomil $0.1 \%$; B2, benomil $0.2 \%$; $\mathrm{K} 1$, Cu-oksida $0.1 \%$; K2, Cu-oksida 0.2\%; KB, campuran antara $1 \mathrm{~g}$ Cu-oksida dan $1 \mathrm{~g}$ $\mathrm{L}^{-1}$ benomil; dan K, kontrol. Percobaan ini diulang sebanyak 3 kali (blok) pada petak percobaan berukuran $5.0 \mathrm{~m} \times 2.5 \mathrm{~m}$.

Bibit nilam ditanam dengan jarak $50 \mathrm{~cm} \times$ $50 \mathrm{~cm}$ dan dibiarkan sampai tanaman saling menutup kemudian dipangkas. Dua minggu setelah dipangkas, tanaman digunakan untuk percobaan. Tanaman nilam disemprot dengan fungisida sesuai perlakuan sebanyak delapan kali dengan selang waktu satu minggu. Intensitas penyakit diamati sebelum tiap kali penyemprotan. Pengamatan intensitas penyakit dilakukan dengan cara skoring pada 10 tanaman sampel per plot. Nilai skor ialah sebagai berikut:

0 , tanaman sehat (tidak bergejala); 1 , bergejala $0-25 \% ; 2$, Bergejala $>25-50 \% ; 3$, bergejala $>50-75 \%$; 4, bergejala $>75 \%$.

Panen nilam dilakukan dua minggu setelah penyemprotan yang ke-8. Daun dikeringkan di bawah sinar matahari selama satu minggu. Rumus intensitas penyakit adalah sebagai berikut:

$$
\mathrm{IP}=\frac{\Sigma(\mathrm{nx} \mathrm{v})}{\mathrm{NxV}} \times 100 \% \text {, dengan }
$$

IP, intensitas penyakit; $v$, nilai skoring; $n$, jumlah nilai skor yang sama; $V$, nilai skor tertinggi; $\mathrm{N}$, jumlah sampel yang diamati.

\section{Minyak Nilam}

Sampel daun yang telah dikeringkan sebanyak $10 \mathrm{~g}$ disuling untuk mendapatkan minyak nilam.

\section{Penyakit Budok pada Setek Nilam}

Setek bergejala budok ditanam dalam kantong plastik. Dalam satu plot disusun secara rapat 100 setek. Perlakuan fungisida sama seperti perlakuan pada pertanaman nilam, yaitu benomil $0.1 \%$ dan $0.2 \%$, Cu-oksida $0.1 \%$ dan $0.2 \%$, campuran $1 \mathrm{~g} \mathrm{Cu}$-oksida dan 
$1 \mathrm{~g} \mathrm{~L}^{-1}$ benomil, dan tanpa fungisida sebagai kontrol. Penyemprotan dilakukan empat kali dengan selang waktu dua minggu.

Panen daun nilam dilakukan tiga minggu setelah penyemprotan terakhir. Minyak nilam dihitung per $10 \mathrm{~g}$ daun kering. Analisis daun nilam hasil panen dan minyak nilam dilakukan dengan anova, uji beda nyata dengan DMRT pada $\alpha 5 \%$.

\section{Analisis Residu Fungisida pada Pertanaman Nilam}

Residu benomil pada daun nilam dianalisis dengan metode HPLC (Naviekiene et al. 2007). Sebanyak $25 \mathrm{~g}$ sampel daun kering diekstrak dengan $200 \mathrm{~mL}$ etil asetat. Ekstrak ditambah dengan 2 tetes dioksan dan disaring. Filtrat diuapkan dengan rotavor pada suhu $40{ }^{\circ} \mathrm{C}$ sampai hampir kering dan ditambah dengan diklormetan sampai volume $5 \mathrm{~mL}$ dan untuk pembersihan menggunakan kolom florisil $10 \mathrm{~cm}$. Elusi dengan diklormetan dilakukan sampai ekstrak menjadi jernih. Ekstrak diuapkan lagi dengan rotavor sampai volume menjadi $5 \mathrm{~mL}$. Selanjutnya analisis residu benomil dilakukan dengan HPLC menggunakan eluen:metanol pada panjang gelombang $285 \mathrm{~nm}$, limit deteksi $0.008 \mathrm{ppm}$.

Analisis residu $\mathrm{Cu}$ dilakukan dengan metode atomic adsorbtion spectrophotometer (AAS). Metode ekstraksi sampel daun kering menggunakan metode Chapman dan Pratt (1961) yang dimodifikasi. HClnya diganti $\mathrm{HNO}_{3}$ dan $\mathrm{HClO}_{4}$. Bubuk daun nilam dikeringkan pada suhu $80{ }^{\circ} \mathrm{C}$ selama 12 jam. Satu gram dari bubuk kering dimasukkan ke dalam gelas piala dan ditambah dengan $5 \mathrm{~mL}$ $\mathrm{HNO}_{3}$ dan $2 \mathrm{~mL} \mathrm{HClO}_{4}$ lalu ditutup dengan gelas arloji dan didestruksi dengan pemanasan sampai volume menjadi 3-5 mL. Larutan ini diuapkan sampai hampir kering dan ditambah dengan 10-15 mL akuabides, kemudian disaring dengan kertas saring bebas asam, dan dimasukkan ke dalam labu takar $50 \mathrm{~mL}$. $\mathrm{Cu}$ dalam ekstrak dianalisis dengan AAS.

\section{HASIL}

Tanaman nilam sakit menunjukkan gejala budok dengan daun dan batang bergejala menyerupai karat, namun tidak berspora. Oleh sebab itu, penyakit ini disebut juga sebagai penyakit karat palsu (Gambar 1).

\section{Penyakit Budok pada Pertanaman Nilam}

Penyemprotan dengan benomil $0.1 \%$ selama delapan kali dengan selang waktu satu minggu, dapat menurunkan intensitas penyakit budok pada nilam secara nyata. Pada plot yang diperlakukan dengan benomil $0.1 \%$ terlihat penurunan intensitas penyakit sampai $0.83 \%$ setelah delapan kali penyemprotan. Pengendalian dengan benomil juga secara nyata berpengaruh terhadap bobot basah daun nilam. Tanaman tampak lebih subur dibandingkan dengan perlakuan lainnya. Semua perlakuan tidak menunjukkan perbedaan hasil minyak nilam per $10 \mathrm{~g}$ bobot kering. Meskipun demikian, penurunan hasil tetap terjadi disebabkan perbedaan bobot basah yang dihasilkan dari setiap perlakuan (Tabel 1).

\section{Residu Fungisida dalam Daun Nilam}

Berdasarkan analisis kimia, daun nilam kering masih mengandung residu benomil dan tembaga. Hasil analisis residu benomil dengan HPLC menunjukkan bahwa Rt (waktu retensi) 2.9 menit. Residu benomil terdeteksi $54 \mathrm{ppb}$ pada perlakuan penyemprotan dengan $0.1 \%$, sedangkan pada perlakuan $0.2 \%$ terdeteksi sebesar 74 ppb (Tabel 2). Benomil adalah fungisida sistemik yang terserap oleh jaringan tanaman. Oleh karena itu, fungisida ini tidak dapat tercuci oleh air hujan dan masih meninggalkan residu dalam jaringan tanaman.

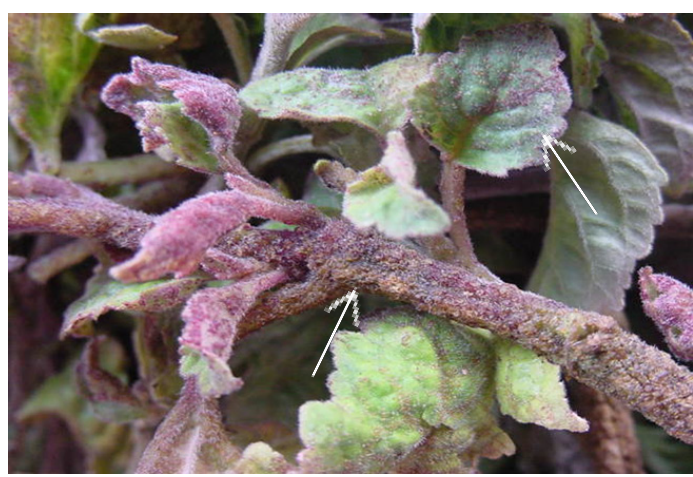

Gambar 1 Gejala penyakit budok pada batang dan daun nilam. Pada batang dan daun terlihat bintil-bintil kasar berwarna kecokelatan. 
Tabel 1 Intensitas penyakit budok dan bobot basah tanaman nilam dan minyak nilam dengan perlakuan fungisida

\begin{tabular}{|c|c|c|c|}
\hline Perlakuan & $\begin{array}{c}\text { Intensitas penyakit* } \\
(\%)\end{array}$ & $\begin{array}{l}\text { Bobot basah daun* } \\
(\mathrm{kg})\end{array}$ & $\begin{array}{c}\text { Minyak nilam } \\
\text { (mL } 10 \mathrm{~g}^{-1} \text { bobot kering) }\end{array}$ \\
\hline B1 & $0.83 \mathrm{a}$ & $9.83 \mathrm{a}$ & 0.300 \\
\hline B2 & $24.17 \mathrm{~b}$ & $5.67 \mathrm{a}$ & 0.290 \\
\hline K1 & $50.83 \mathrm{~b}$ & $4.50 \mathrm{a}$ & 0.330 \\
\hline $\mathrm{K} 2$ & $54.17 \mathrm{~b}$ & $3.40 \mathrm{a}$ & 0.280 \\
\hline KB & $35.00 \mathrm{~b}$ & $4.40 \mathrm{a}$ & 0.300 \\
\hline $\mathrm{K}$ & $100.00 \mathrm{c}$ & $2.83 \mathrm{~b}$ & 0.290 \\
\hline
\end{tabular}

B1, benomil 0.1\%; B2, benomil 0.2\%; K1, Cu-oksida $0.1 \%$; K2, Cu-oksida $0.2 \%$; KB, campuran antara $1 \mathrm{~g} \mathrm{Cu}$ oksida dan $1 \mathrm{~g} \mathrm{~L}^{-1}$ benomil; $\mathrm{K}$, kontrol.

*Angka yang diikuti dengan huruf yang sama pada kolom yang sama, menunjukkan tidak beda nyata berdasarkan DMRT $5 \%$; Data tidak dianalisis.

Perkembangan Penyakit Budok pada Setek Nilam

Hasil penelitian menunjukkan bahwa bibit yang bergejala budok masih dapat ditanam dengan pengendalian menggunakan benomil $0.1 \%, 0.2 \%$, tembaga oksida $0.1 \%, 0.2 \%$ dan campuran keduanya. Penyemprotan dilakukan empat kali dengan selang waktu dua minggu. Pada akhir pengamatan sebelum panen terlihat bahwa semua bibit mengalami penyembuhan penyakit. Penyemprotan dengan benomil menunjukkan bobot daun nilam lebih baik dibandingkan dengan perlakuan lainnya (Tabel 3).

\section{PEMBAHASAN}

Tanaman nilam dengan kerusakan yang berat akibat penyakit budok memerlukan pengendalian secara kimiawi. Penyemprotan dengan fungisida benomil dengan kepekatan $0.1 \%$ delapan kali dengan selang waktu satu minggu dapat secara nyata menurunkan intensitas penyakit, sebaliknya penyemprotan dengan kekerapan yang sama pada kepekatan $0.2 \%$ kurang dapat menurunkan kerusakan meskipun tetap lebih rendah dibandingkan dengan yang tidak disemprot benomil. Hal ini diduga kepekatan benomil yang tinggi dapat merusak daun. Kerusakan nekrotik dapat mengakibatkan kerusakan parah setelah terjadi serangan penyakit budok. Telah diketahui pula bahwa benomil adalah fungisida sistemik yang mempunyai risiko
Tabel 2 Residu benomil dan $\mathrm{Cu}$ dalam daun nilam kering

\begin{tabular}{lcc}
\hline Perlakuan & Benomil $(\mathrm{ppb})$ & $\mathrm{Cu}(\mathrm{ppm})$ \\
\hline B1 & 54 & 75.37 \\
$\mathrm{~B} 2$ & 74 & 19.36 \\
K1 & - & 959.05 \\
K2 & - & 438.52 \\
KB & 100 & 163.82 \\
Kontrol & - & 18,83 \\
\hline
\end{tabular}

B1, benomil 0.1\%; B2, benomil 0.2\%; K1, Cu-oksida $0.1 \%$; $\mathrm{K} 2, \mathrm{Cu}$-oksida $0.2 \%$; $\mathrm{KB}$, campuran antara $1 \mathrm{~g} \mathrm{Cu}$-oksida dan $1 \mathrm{~g} \mathrm{~L}^{-1}$ benomil; $\mathrm{K}$, kontrol. -, tidak dianalisis.

Tabel 3 Bobot basah hasil tanaman nilam berpenyakit budok yang diperlakukan dengan fungisida

\begin{tabular}{lc}
\hline Perlakuan & Bobot basah* $(\mathrm{g})$ \\
\hline B1 & $1733.33 \mathrm{~b}$ \\
B2 & $1775.00 \mathrm{~b}$ \\
K1 & $1141.66 \mathrm{a}$ \\
K2 & $1575.00 \mathrm{a}$ \\
KB & $1633.33 \mathrm{a}$ \\
Kontrol & $1141.00 \mathrm{a}$ \\
\hline
\end{tabular}

B1, benomil 0.1\%; B2, benomil 0.2\%; K1, Cu-oksida $0.1 \%$; $\mathrm{K} 2$, Cu-oksida $0.2 \%$; $\mathrm{KB}$, campuran antara $1 \mathrm{~g} \mathrm{Cu}$-oksida dan $1 \mathrm{~g} \mathrm{~L}^{-1}$ benomil; $\mathrm{K}$, kontrol. *Angka yang diikuti dengan huruf yang sama menunjukkan tidak beda nyata berdasarkan DMRT 5\%.

tinggi untuk menimbulkan galur patogen tahan berdasarkan fungicide resistance action committe (FRAC). Bila dikombinasikan dengan patogen yang mempunyai sporulasi 
yang melimpah risiko untuk menjadi tahan terhadap patogen menjadi bertambah tinggi Budok adalah penyakit dengan sporulasi yang melimpah sehingga penggunaan fungisida sistemik perlu dikombinasikan dengan kontak seperti fungisida yang berbahan aktif tembaga. Hal ini akan terjadi bila penyemprotan dengan benomil dilakukan terus-menerus. Pengendalian dengan fungisida sistemik termasuk benomil yang digunakan terusmenerus akan menimbulkan galur cendawan tahan fungisida (Sumardiyono 2008). Keadaan yang demikian tidak menguntungkan mengingat tanaman nilam dapat dipanen beberapa kali setelah pangkas. Residu yang masih tertinggal pada bahan tanaman setelah pangkas dapat memicu timbulnya galur cendawan tahan fungisida. Dengan melihat hasil penyemprotan dengan fungisida tembaga yang masih lebih rendah dengan yang tidak disemprot maka penyemprotan dengan fungisida ini dapat dilakukan secara berselang-seling dengan benomil. Pada kondisi kerusakan moderat fungisida golongan tembaga dapat menjadi alternatif. Fungisida dengan bahan aktif campuran sistemik dan kontak atau fungisida berbahan aktif yang berbeda cara kerjanya dapat dipakai untuk mengatasi masalah munculnya galur tahan fungisida. Penggunaan fungisida dengan kode FRAC yang berbeda merupakan metode untuk keberhasilan manajemen ketahanan cendawan terhadap fungisida (Werling 2013). Triadimefon yang juga fungisida sistemik yang mempunyai cara kerja yang berbeda dengan benomil dapat digunakan untuk pengendalian penyakit ini (Kusnanta 2005). Dalam daun yang tidak diperlakukan dengan fungisida tembaga terdeteksi adanya residu tembaga. Hal ini disebabkan dalam daun setiap tanaman terdapat kandungan tembaga bawaan meskipun tidak disemprot dengan fungisida apa pun (kontrol). Hasil pengamatan visual pertanaman yang disemprot dengan benomil lebih baik daripada perlakuan lainnya. Hal ini terlihat juga pada jumlah hasil panen. Keadaan yang demikian terjadi karena benomil mempunyai efek seperti sitokinin yang memacu pertumbuhan tanaman dan menunda penuaan daun (Akindo et al. 2006). Berdasarkan hasil penelitian ini, residu benomil terdeteksi pada tingkat yang sangat rendah. Batas maksimum residu (BMR) untuk tanaman nilam sampai saat ini belum ada peraturannya, sedangkan berbagai tanaman pertanian memiliki BMR bervariasi antara $0.1 \mathrm{ppm}$ dan 50.0 ppm. Demikian juga BMR untuk golongan fungisida tembaga belum ada ketentuannya. Meskipun peraturan tentang BMR pada nilam belum ada, untuk keperluan ekspor nilam, residu yang rendah mengindikasikan keamanan produk yang dihasilkan. Hasil penelitian juga mennnjukkan bahwa setek yang terinfeksi budok dapat disembuhkan dengan penyemprotan benomil. Hal ini perlu dilakukan mengingat setek yang sehat akan lebih menjamin tanaman selanjutnya untuk menjadi sehat

\section{UCAPAN TERIMA KASIH}

Terima kasih dan penghargaan disampaikan kepada Litbang Deptan yang telah memberikan dana melalui KKP3T 2008 dan 2009 dan Muhadi yang telah membantu penelitian lapangan.

\section{DAFTAR PUSTAKA}

Akindo OSA, Ogunbayo KA, Sanni, Ojo AO. 2006. Effect of different rates and methods of benomyl and mancozeb application on delay in senescens and grain yield of cowpea (Vigna unguiculata (L)Walp) under different cropping season. Afr J Biotechnol. 5(17):1545-1550.

Chapman HD, Pratt PF. 1961. Method of Analysis for Soil Plants and Water. Berkeley (US): University of California.

Kusnanta MA. 2005. Identifikasi dan pengendalian penyakit karat palsu pada nilam (Pogostemon cablin) dengan fungisida. [tesis]. Yogyakarta (ID): Universitas Gadjah Mada.

Naviekiene S, Posidonio O, de Amarante Junior, Brito MB, Graciolli L, Ribero ML. 2007. Determination of benomyl residue in shiitake mushroom (Lentinula edodes) 
by Liquid chromatography UV detection. Werling, B. 2013. FRAC code help in fungicide J Chromatography. 45(6):340-344.

Sumardiyono C. 2008. Ketahanan jamur resistance management. Michigan State terhadap fungisida di Indonesia. J Perl Tan Indones. 14(1):1-5.

Wahyuno D. 2010. The life cycle of Synchytrium pogostemonis on Pogostemon cablin. Microbiol Indones. 4(3):127-131. University. http://msue.anr.msu.edu/news/ frac_codes_help_in_fungicide_resistance management. [diakses 19 Mei 2014]. 